Bangl. J. Vet. Med. (2006). 4 (1): 31-37

\title{
GROSS ANATOMY OF THE AORTIC VALVE OF INDIGENOUS CATTLE (BOS INDICUS) OF BANGLADESH
}

\author{
M. N. Islam*, M. Z. I Khan, S. R. Khan ${ }^{1}$ and M. A. Haque ${ }^{2}$ \\ Department of Anatomy and Histology, Faculty of Veterinary Science, Bangladesh Agricultural University, \\ Mymensingh-2202, Bangladesh
}

\begin{abstract}
The present research work was carried out to study the gross anatomy of the aortic heart valve of indigenous cattle (Bos indicus) for future bioprosthetic use in human in the Department of Anatomy and Histology, Bangladesh Agricultural University, Mymensingh during the period from January to December 2004. A total of 32 (thirty two) aortic heart valves of cattle were fixed in $10 \%$ formalin for the present study. The components of the aortic valve studied were the aortic leaflets, sinuses, interleaflet (in between the cusps) triangles, aortic root, annulus and ossa cordis. In the present study, the aortic valve leaflets or cusps of the cattle heart were semilunar in shape and three in number e.g. right coronary, left coronary and noncoronary cusp. Each leaflet of the valve had a central lamina fibrosa at their free margin. The lamina fibrosa was most of the thickened part of the cusps in the mid point of the lunula, which forms the fibrous nodules, or corpus arantii of each leaflet. When the valve was closed, the three nodules meet centrally. The leaflets were thicker than those of the pulmonary valve and were attached to the ventricular myocardium by aortic annulus.The aortic root of bovine heart contained the three cusps, sinotubular junction, vulsalva's sinuses, commissures and interleaflet triangles. The left and right coronary arteries were emerged from the left and the right coronary ostium located in the aortic or vulsalva's sinuses of aortic valve respectively. The annulus in the cattle heart had three arches, e.g. anterior arch, left arch and right arch. The findings of the present research work revealed the similarities of the anatomical structures of the aortic valve cusps of the cattle heart as compared with other animals and human being. The variation was only the presence of ossa cordis in cattle species in the present study.
\end{abstract}

Key words: Gross anatomy, aortic valve, heart, indigenous cattle

\section{INTRODUCTION}

The gross anatomical study of the aortic valve is important for the success of implantation of the valve in man and animal. In this regard, various tissues of porcine and bovine origin are used to construct bioprosthetic valves for aortic and other valve replacement in human. However, before bioprosthesis it is important to know the gross anatomical structures of the aortic valve. In healthy animals, the aortic valve is made up of three cusps of similar size. The malformed valves with a bigger or smaller number of cusps are common in diseased animals only. Specific studies of the gross anatomy of the aortic valve of the heart of cattle and sheep, horse, dog and pig were carried out by Getty (1975). Trotter and Lumb (1958) were found that the circular aortic orifice carries the aortic valve consisted of three semilunar cusps which were stronger than those of the pulmonary valves of the bovine heart. In bovine, the aortic valve were also consisted of three cusps, which were semilunar in shaped, and stronger than those of the pulmonary valves. These valves consisted principally of three cusps, aortic annulus, aortic wall, aortic root, valsalva's sinus and sinotubular junction (Thubrikar et al., 1986, Mercer and Robotham, 1992; Sutton et al., 1995). In addition, ossa cordis were also present in the aortic annulus of the bovine heart (Islam et al., 2002). The gross anatomical studies of the heart valve was carried out in different species of animals including cattle, however, their anatomical studies in the indigenous cattle of Bangladesh which have possibilities for bioprostheses is yet to be done. Therefore, the present study has been carried out to investigate the gross anatomical structures of the aortic valve of indigenous cattle of Bangladesh.

Present address: ${ }^{*}$ Corresponding author, Department of Anatomy and Histology, Sylhet Government Veterinary College, Tilagor, Sylhet, ${ }^{1}$ Bagladesh Heart Research Association, Dhaka, Bangladesh, ${ }^{2}$ Department of Surgery and Obstetrics, Bangladesh Agricultural University, Mymensingh-2202, Bangladesh. 


\section{MATERIALS AND METHODS}

This study was conducted on 32 aortic valves of indigenous cattle (Bos indicus) in the Department of Anatomy and Histology, Faculty of Veterinary Science, Bangladesh Agricultural University, Mymensingh during the period January to December 2004. The cattle were grouped into 2, 2.5, 3 and 4 years of age of both sexes (50\% male and $50 \%$ female). The heart specimens were collected from the slaughter house immediately after slaughtering the apparently healthy cattle with aseptic measures. The specimens were carried to the laboratory by a thermo flask in a polythene bag containing ice. After rinsing away the blood, the hearts were kept in the balanced isotonic saline solution until dissection in the laboratory. The aortic valves were harvested by dissection of the collected heart specimans and fixed in 10\% formalin and embedded with cotton plug just after harvesting for keeping valve cusps in normal shape. Great care was taken during trimming of excess myocardium from the end of the aortic root.

The gross anatomical studies of the aortic valve of the indigenous cattle with their supporting structures were done with the following parameters:

\section{The aortic valve cusps or leaflets of bovine heart}

The aortic valve is named for the shape of its cusps. The cusps are cup-like, passive soft tissue structures attached to the wall of the aorta. In the present study the gross morphology of the free surface of the cusps, corpus arantii (or nodulus of Arantus), commissures, attachment of the cusp with the aortic wall and fibrosal surface as well as ventricular surface of the cusps have been undertaken (Fig.1-2).

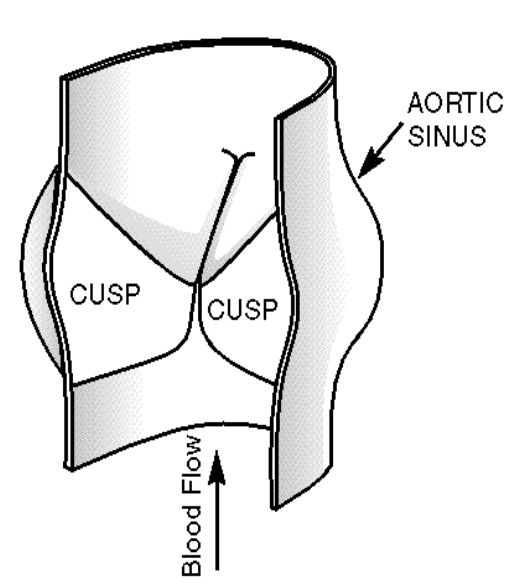

Fig. 1

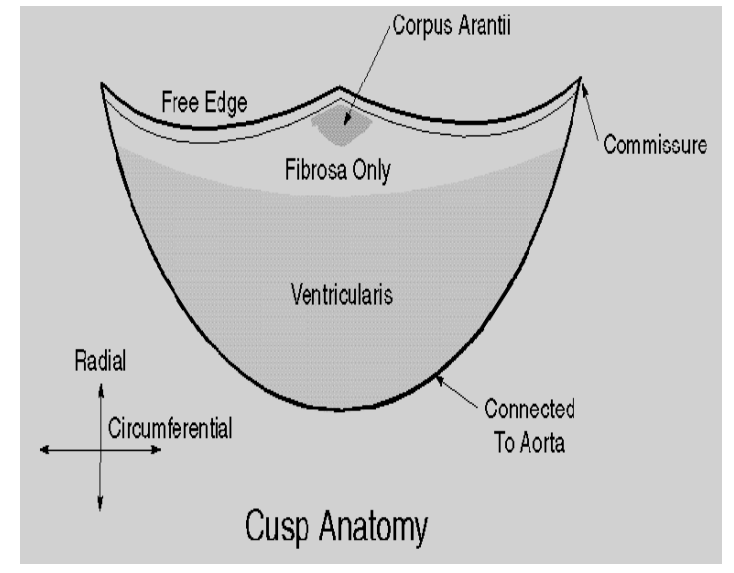

Fig. 2

Fig. 1. A sketch demonstrating the aortic valve in its normal orientation with one cusp removed, Fig. 2. A sketch demonstrating the anatomy of the cusp of aortic valve. The sketch showing the inner surface (fibrosa) of the cusp towards the aorta and the outer surface (ventricularis) of the cusp towards the ventricle of the heart.

\section{The aortic root}

The aortic root may be defined as the portion of the left ventricular outflow tract which supports the leaflets, sinuses, commissures, and the interleaflet triangles showing in the Fig. 3.

\section{The aortic annulus}

It is a ring-shaped structure surrounding the aortic valve. A ring of tough fibrous tissue at the base of the heart. This ring supports and anchors the heart valve(s) into the heart itself (Fig. 4). 


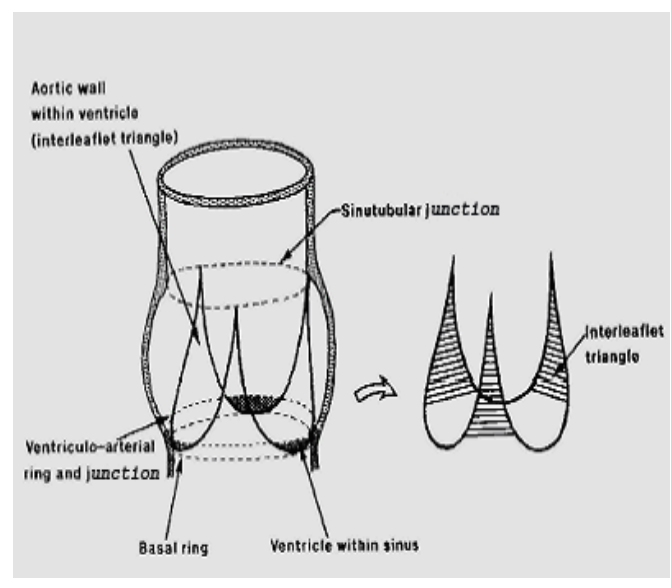

Fig. 3

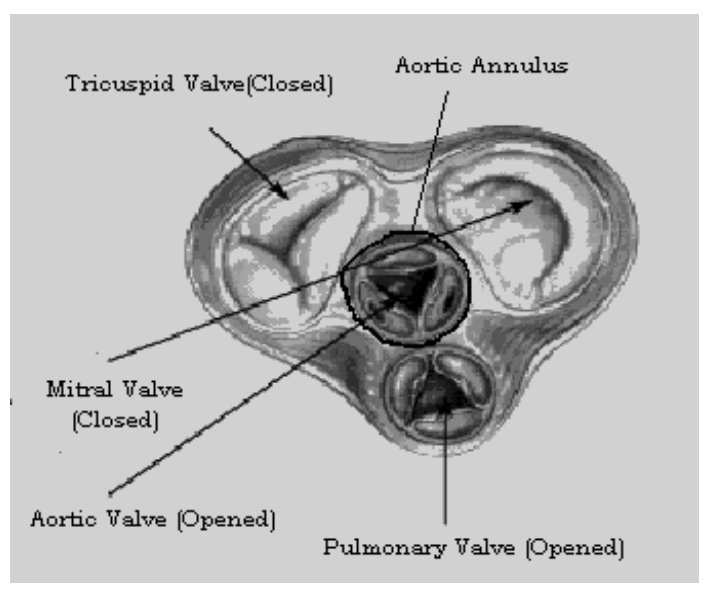

Fig. 4

Fig. 3. A diagrammatic representation of the aortic root shows its considerable length. The leaflets are attached within the cylinder of the root in the form of a coronet, Fig. 4. Fibrous skeleton of the heart showing the valve annulus in the aortic ring (aortic annulus) where the aortic valve is separated from the left ventricle of the heart.

\section{The ossa cordis of bovine heart}

These were two irregularly triangular, semiosseous structures present in the aortic ring or annulus and adjacent part of the ventricular wall.

\section{Photographs of the gross specimen}

The photographs were made during the course of study from the gross specimen and placed in the research article for proper illustration.

\section{RESULTS AND DISCUSSION}

In the present study, the aortic valve leaflets of cattle heart were three in number: right, left and noncoronary, each leaflet of the valve had a central lamina fibrosa at their free margin of which the thickened part in the mid point of the lunula formed the corpus arantii. The aortic surface of the cusps being rougher in nature than the ventricular surface in the present study (Fig. 6-7). Similar findings were reported by Anastasios and Inderjit (2002) in human indicating that morphologically the aortic heart valve of human and animals are similar. This result shows future possibilities of bioprosthesis.

The aortic valve possesses three semilunar leaflets and these were thicker and stronger than pulmonary valve in the present study, which was similar to the report in bovine (Trotter and Lumb, 1958; Getty, 1975) and in human heart (William, 1995). In horse, dog and pig similar results were also observed by Getty (1975). Angelini et al. (1989) reported that due to congenital defect the contents of the valve in human are inadequate. All these findings indicated that for normal outflows of the blood through the aorta needs three leaflets and the two leaflets found only in abnormal cases.

Regarding the attachment of the aortic valve, it was found in the present study that the cusps of the cattle aortic valve were attached to the base of aortic root distally and to the ventricular myocardium by aortic annulus proximally. The commissures were the attachment points at the ends of the free edge of the leaflets of aortic valve and it was located below the sinotubular junction. David (2003) reported that the aortic cusps of human are attached to the aortic annulus in a scalloped fashion. The highest point where two cusps meet is called the commissure, and it is located similar to the present finding in cattle. Anderson (2000) reported a similar findings in deviated forms in human that the leaflets of the aortic valve are attached within a cylinder extending to the sinotubular junction of the aorta. He also added that the semilunar attachments of the leaflets themselves form the haemodynamic junction between left ventricle and aorta (Sakakibara and Konno, 1962). 


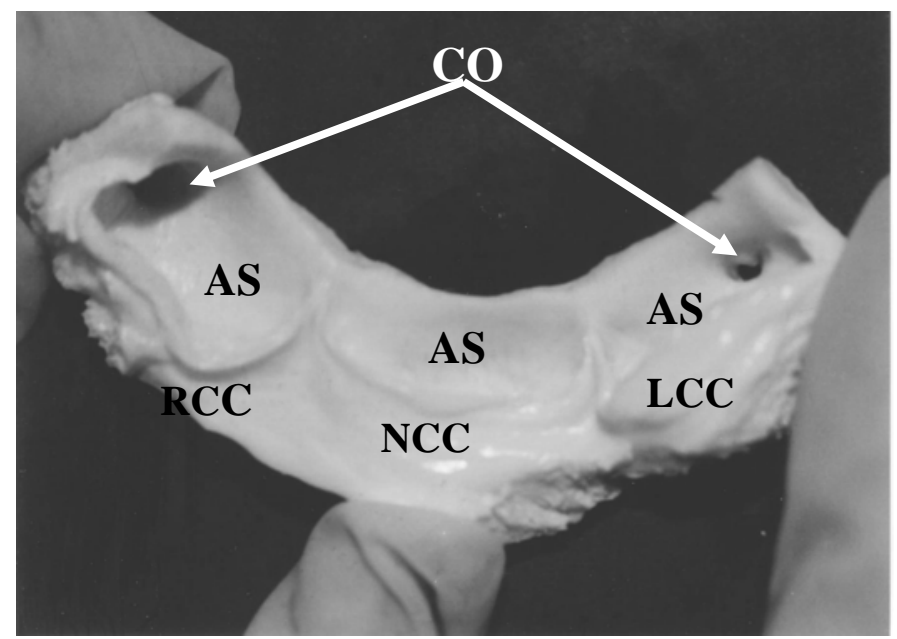

Fig. 5

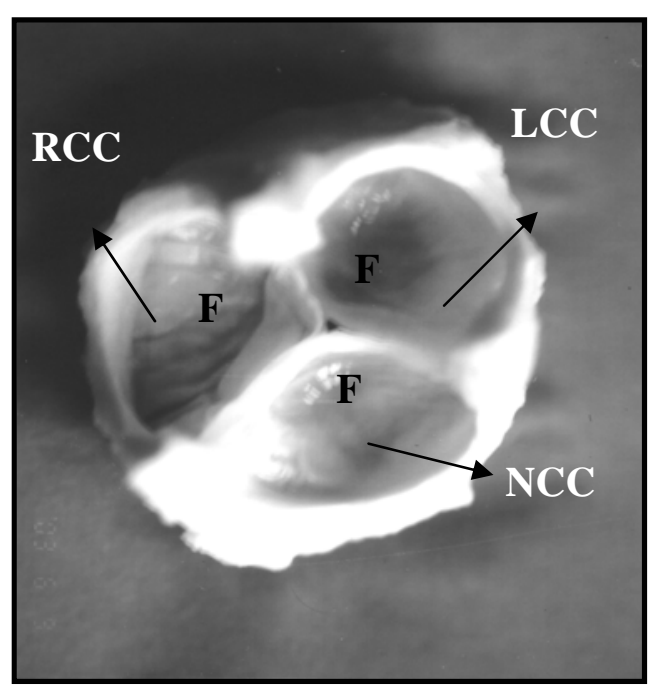

Fig. 6

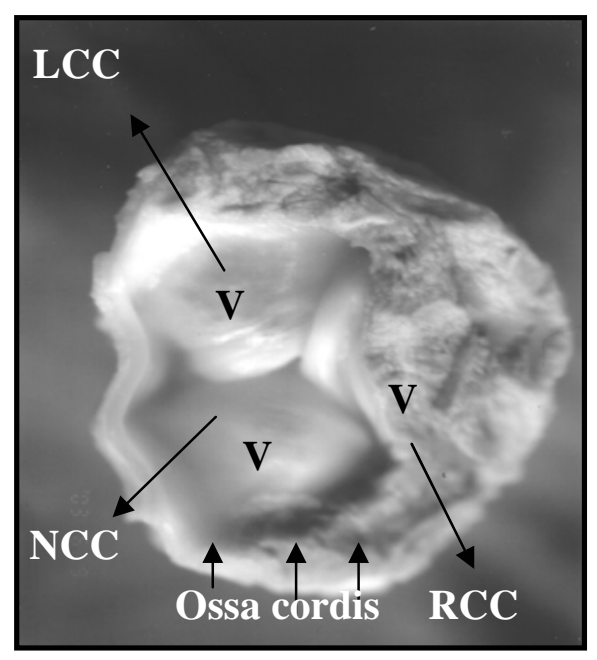

Fig. 7

Fig. 5. Photograph of an aortic valve of cattle heart showing three cusps, right coronary cusp (RCC), left coronary cusp (LCC) and non coronary cusp (NCC) with aortic sinuses (AS). The coronary ostia (CO) are located in the RC sinus and LC sinus, Fig. 6. Photograph of an aortic valve of cattle heart in subcoronary position showing the fibrosal sides (F) of three cusps, right coronary cusp (RCC), left coronary cusp (LCC) and non coronary cusp (NCC) and Fig. 7. Photograph of an aortic valve of cattle heart in subcoronary position showing the ventricular sides (V) of three cusps, right coronary cusp (RCC), left coronary cusp (LCC) and non coronary cusp (NCC) and ossa cordis in the aortic annulus.

In the present study, it was found that the aortic root of cattle heart composed of three cusps, sinotubular junction, vulsalva's sinuses, commissures and interleaflet triangles. The left and right coronary arteries were emerged from the left and the right coronary sinuses located in the vulsalva's sinuses of aortic valve respectively (Fig. 5). Similarly, David (2003) reported that the aortic valve of human is a complex structure that is best described as a functional and anatomic unit called the aortic root. He found that the aortic root of man has four 
components e.g. aortic annulus, aortic cusps, aortic sinuses (sinuses of Valsalva), and sinotubular junction. He also added that the left coronary artery like bovine arises from the left aortic sinus and the right coronary artery arises from the right aortic sinus.

The geometry of the aortic root and its anatomic components varied among individuals, but the geometry of these components is somewhat interrelated (Kunzelman et al., 1994; Grande-Allen et al., 2000; Swanson and Clark, 1974; Silver and Roberts, 1985). For instance, the larger the aortic cusps, the larger the diameters of the aortic annulus and sinotubular junction (Silver and Roberts, 1985). Sutton et al. (1995) reported that the aortic root is a three-dimensional structure made up of the sinuses of Valsalva, the leaflets of the valve and the interleaflet triangles.

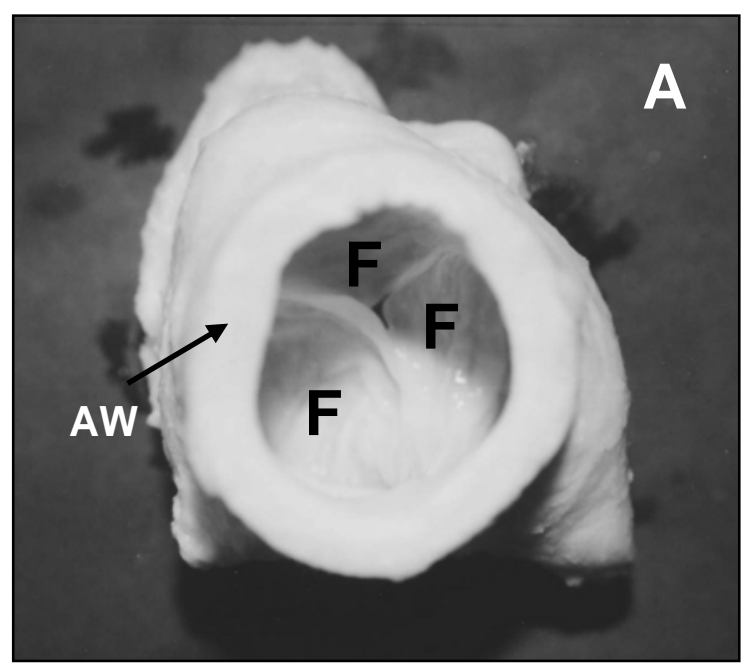

$\underline{\text { Aortic view }}$

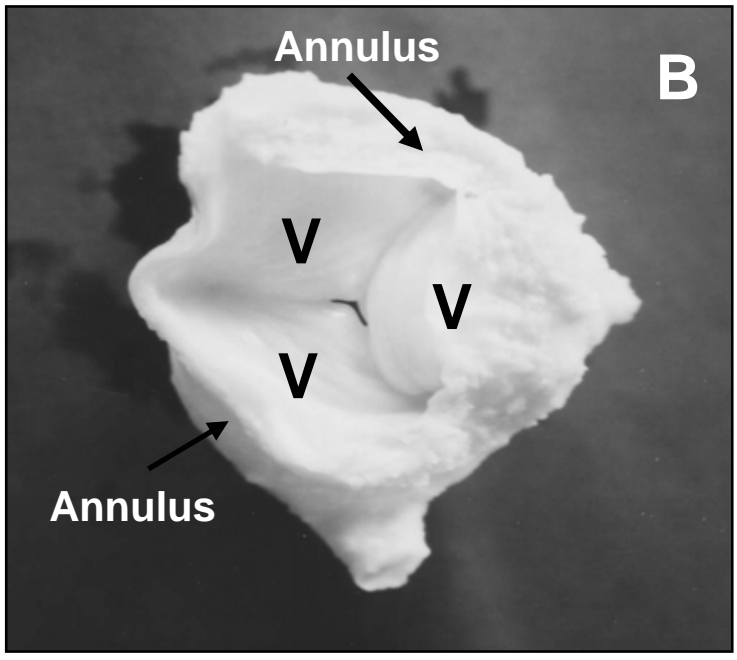

Ventricular view

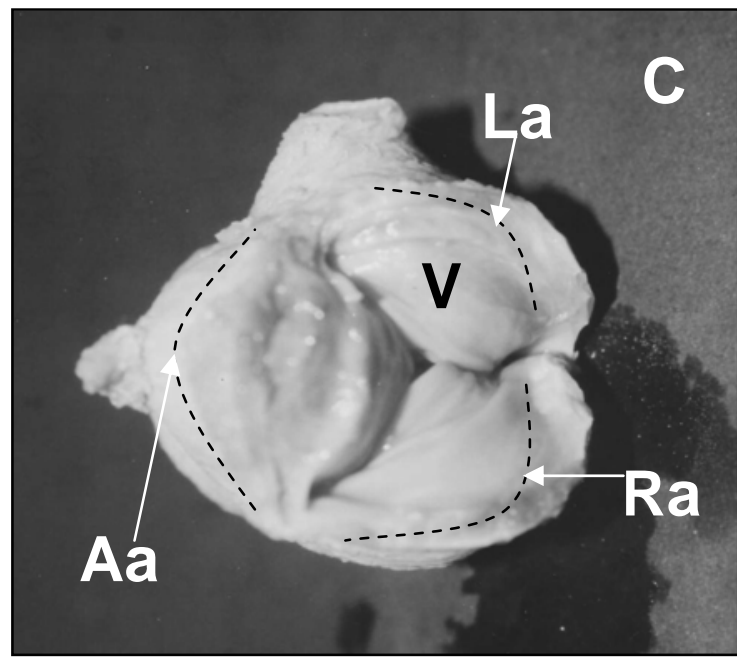

$\underline{\text { Ventricular view }}$

Fig. 8. A, B: Aortic valves of bovine heart (Fixed in $10 \%$ formalin solution), C: Aortic valves of bovine heart (Fixed in $2.5 \%$ buffered gluteraldehyde solution). These photographs showing the fibrosa (F) in the aortic view and ventricularis (V) in the ventricular view of the cattle heart aortic valves. The annulus of aortic valve (C) is arranged as three arches, e.g. anterior arch (Aa), left arch (La) and right arch (Ra). 
The three sinuses of Valsalva occupy the greater part of the aortic root. The sinuses are the dilatations of the aortic wall confined proximally by the bases of the semilunar valve leaflets and distally by the sinotubular ridge. Yacoub et al. (1999) reported that the aortic root as a whole is divided by the semilunar attachment of the leaflets of aortic valve into supravalvar and subvalvar components. The supravalvar components are the aortic sinuses, but they contain at their base structures of ventricular origin. The supporting subvalvar parts are primarily ventricular, but extend as three triangles to the level of the sinotubular junction. From these findings it is clear that the aortic root of cattle heart contains aortic annulus, aortic cusps, and sinotubular junction which are similar to that of human, and plays an important role in maintaining valve competence. On the other hand, the aortic sinuses play no role in valve competence.

Regarding the basic anatomy of the aortic annulus, it was revealed in the present study that the annulus in the bovine heart was arranged as three arches e.g. anterior arch, left arch and right arch (Fig. 8). These included the anterior sheet of fibrous tissue between the fibrous annuli of the cranial and left caudal aortic valve leaflets that merges with the tendon of the infundibulum subaortic curtain pars membranacea septi. McMorran (2004) reported that the aortic valve annulus of human also contain anterior, left and right arches. These arches are the fibrous skeleton of the heart. Yacoub et al. (1999) meant that an annulus is no more than a ring. In this respect, he suggested that the aortic root can be removed from the heart, and slipped on the finger in the form of a ring. Within the ring, the leaflets were supported as crown-like fashion.

In the present study, the fibrocartilaginous, irregularly triangular and semiosseous structures, the ossa cordis was found in the aortic ring and the adjacent part of the ventricular wall of cattle heart ( Fig. 7 ). In this relation, Getty (1975) noted that two bones, the ossa cordis develop in the aortic fibrous ring of the heart of cattle and sheep. In this regard, Trotter and Lumb (1958) also described that the ossa cordis of bovine are two irregularly triangular, semiosseous structures in the aortic ring and adjacent part of the ventricular wall. The right bone was larger and was related to the attachment of the right posterior cusp of the aortic valve. The ossa cordis appeared to be entirely cartilaginous in young animals. Previously, Islam et al. (2002) noted the presence of ossa cordis in the aortic fibrous ring. In this regard literatures were not available regarding the ossa cordis of human and other domesticated animals suggesting that the ossa cordis is confined within the heart of bovine only.

Therefore, it is concluded from the above discussion that all the gross anatomical structures of the aortic valve including annulus and aortic root of heart of indigenous cattle are nearly similar to the structures of the aortic valve of other species of animal and human heart.

\section{REFERENCES}

1. Anastasios KK and Inderjit SG (2002). Surgical Anatomy of the Heart. Cardiac Valves, Aortic valve: Section 6 of 9 (http://www.emedicine.com/ped/byname/ surgical-anatomy-of-the-heart.htm).

2. Anderson RH (2000). Clinical anatomy of the aortic root. Heart 84:670-673.

3. Angelini A, Ho SY, Anderson RH, Devine WA, Zuberbuhler JR, Becker AE and MJ Davies (1989). The morphology of the normal aortic valve as compared with the aortic valve having two leaflets. Journal of Thoracic and Cardiovascular Surgery 98: 362-367.

4. David TE (2003). Aortic Valve Repair and Aortic Valve-Sparing Operations. In: Cohn LH, Edmunds LH Jr, (eds), Cardiac Surgery in the Adult. McGraw-Hill, New York.

5. Getty R (1975). Sisson and Grossman`s the Anatomy of the Domestic Animals. Vol. 1, 5 ${ }^{\text {th }}$ edn., W. B. Saunders Company, Philadelphia, USA.

6. Grande-Allen KJ, Cochran RP, Reinhall PG (2000). Recreation of sinuses is important for sparing the aortic valve: a finite element study. Journal of Thoracic and Cardiovascular Surgery 119: 753.

7. Islam MN, Mazumder MS, Islam KN, Mahbub-e-Elahi ATM and Khan SR (2002). Investigation of bovine aortic valves in cardiac research for bioprosthetic purpose. Pakistan Journal of Biological Science 5: 101-103.

8. Kunzelman KS, Grande KJ, David TE., Cochran RP and Verrier ED (1994). Aortic root and valve relationships: Impact on surgical repair. Journal of Thorac and Cardiovascular Surgery 107: 162-170.

9. McMorran J (2004). Aortic valve annulas (anatomy). General Practice Notebook - a UK medical encyclopedia on the World Wide Web.

10. Mercer JL and Robotham K (1992). A comparison between the inlet and outlet diameters of the normal aortic valve. Journal of Biomechanics 25: 1363.

11. Sakakibara S and Konno S (1962). Congenital aneurysm of the sinus of Valsalva: a clinical study. American Heart 63:708.

12. Silver MA and Roberts WC (1985). Detailed anatomy of the normally functioning aortic valve in hearts of normal and increased weight. American Journal of Cardiology 55: 454-461. 
Anatomy of aortic valve of cattle

13. Sutton III JP, Ho SY, Anderson RH (1995). The forgotten interleaflet triangles: A review of the surgical anatomy of the aortic valve. Annals of Thoracic Surgery 95: 419-427.

14. Swanson WM and Clark RE (1974). Dimensions and geometric relationships of the human aortic valve as a function of pressure. Circulation Research 35: 871.

15. Thubrikar MJ, Nolan SP, Aouad J and Deck JD (1986). Stress sharing between the sinus and leaflets of canine aortic valve. Annals of Thoracic Surgery 42: 434.

16. Trotter DM and Lumb JW (1958). Angiology: The Left Ventricle, Bovine Anatomy. 2nd edn., Burgess Publishing Company, 426 South $6^{\text {th }}$ Street, Minneapolis.

17. William PL (1995). Gray's Anatomy: The Anatomical Basis of Medicine and Surgery. $38^{\text {th }}$ edn., USA Shurchill Livingstone Inc., 650 Avenue, New York, USA.

18. Yacoub MH, Kilner PJ, Birks EJ and Misfeld M (1999). The aortic outflow and root: a tale of dynamism and crosstalk. Annals of Thoracic Surgery 68 (3 Suppl): S37-43. 